\title{
DESCARTES DE ORIGEM ANIMAL E O CRESCIMENTO E GANHO DE PESO DO JACARÉ-DE-PAPO-AMARELO, Caiman latirostris (Daudin, 1802), EM CATIVEIRO
}

\author{
Fabianna Sarkis-Gonçalves ${ }^{1,4}$; Ana Maria Vicente Castro²; Luciano Martins Verdade ${ }^{3^{*}}$ \\ ${ }_{2}^{1}$ Pós-Graduanda em Ciência Animal e Pastagens- USP/ESALQ. \\ ${ }^{2}$ Graduanda em Engenharia Agronômica - USP/ESALQ. \\ ${ }^{3}$ Depto. de Produção Animal, Lab. de Ecologia Animal - USP/ESALQ, C.P. 9 - CEP: 13418-900 - Piracicaba, SP. \\ ${ }^{4}$ Bolsista CAPES. \\ *Autor correspondente <Imv@esalq.usp.br>
}

\begin{abstract}
O custo da alimentação é o principal fator limitante para a criação de jacarés em cativeiro. O uso de descartes e subprodutos como fontes de alimento em fazendas de criação de jacarés poderá auxiliar a resolver este problema. No presente estudo, quatro diferentes tipos de descartes provenientes da produção animal foram avaliados como alimento para o jacaré-de-papo-amarelo (Caiman latirostris) durante o primeiro ano de vida. Um total de 120 filhotes provenientes de seis ninhadas foram mantidos em quatro diferentes tanques dentro de uma estufa plástica. As seguintes dietas foram usadas: peixe, suino, frango e mista (peixe + suino + frango em iguais proporções). O delineamento experimental foi de ANOVA por blocos. Ganho de peso e taxas de crescimento do comprimento rostro-anal e da cintura comercial foram medidos e modelos de crescimento foram estabelecidos. A dieta mista resultou em melhores taxas de crescimento e ganho de peso, mas não foram detectadas diferenças consistentes entre as dietas usadas quanto aos modelos de crescimento. Palavras-chave: manejo de fauna, manejo alimentar, criação de jacarés
\end{abstract}

\section{ANIMAL DISCARDS AND THE GROWTH AND WEIGHT GAIN OF THE BROAD-SNOUTED CAIMAN, Caiman latirostris (Daudin, 1802), IN CAPTIVITY}

\begin{abstract}
Cost of feeding is the main limiting factor of caiman farming. The use of livestock discards and byproducts as food sources in caiman farms might help solving this problem. On the present study, four different livestock discards were evaluated as food for broad-snouted caimans (Caiman latirostris) on the first year of life. A total number of 120 hatchlings from six different clutches were kept in four tanks inside a greenhouse. The following diets were used: fish, swine, chicken, mixed (fish + swine + chicken, equal proportions). The experimental design was based on nested ANOVA. Weight gain and growth rates of snoutvent length and belly-width were measured and growth models established. The mixed diet resulted in best growth rates and weight gain, but no consistent difference in growth models among diets were detected.

Key words: wildlife management, feeding, caiman farming
\end{abstract}

\section{INTRODUÇÃO}

Os crocodilianos são predadores oportunistas, podendo se alimentar de qualquer animal vivo que possam capturar, incluindo os da mesma espécie (Pooley, 1989). Em meio silvestre os filhotes alimentam-se de crustáceos, caracóis e, principalmente, de insetos. Adultos apresentam seletividade oportunista e consomem mamíferos, artrópodes, peixes, aves e répteis (McNease \& Joanen, 1981; Micucci \& Waller, 1995; Diefenbach, 1988).

Vários aspectos devem ser considerados na escolha da alimentação ideal como custo, disponibilidade, facilidade de armazenamento e de manejo, aceitação pelos animais, componentes nutricionais e efeitos sobre as taxas de crescimento e reprodução (Joanen \& McNease, 1981) . A criação em cativeiro tem como principal fator limitante o custo de produção. A alimentação é responsável por 50 a $60 \%$ do custo total de produção (Rodriguez et al., 1996) . Este problema pode ser resolvido através da obtenção e utilização de alimentos de baixo custo, como descartes de produção animal.

A produção avícola é atualmente uma grande geradora de carcaças e refugos, sendo a eliminação desses materiais um problema para seus criadores. Estima-se que a produção de carcaças provenientes de causas não infecciosas seja de aproximadamente 2500 ton./mês no Estado de São Paulo, quantidade suficiente para alimentar 13.000 fêmeas reprodutoras que produziriam 325.000 couros/ano (Verdade et al., 1990). Este tipo de alimento é também utilizado em criações comerciais de crocodilos na África do Sul, Austrália e Papua Nova Guiné (Verdade, 1997a). Em criações de suínos a mortalidade de leitões do nascimento até o desmame pode chegar a $25 \%$ (Walker et al., 1993). Leitões com peso ao nascer abaixo de $0,60 \mathrm{~kg}$ devem ser descartados porque a taxa de mortalidade nessas condições é muita alta (Fireman \& Siewerdt, 1997). 
A produção brasileira de pescado já atingiu em alguns anos aproximadamente um milhão de toneladas anuais e com o enorme potencial pesqueiro, ainda a ser explorado, pode chegar a 4 milhões de toneladas de pescado por ano (Oetterer, 1993/94). Do total de pescado capturado mundialmente, cerca de $28 \%$ são destinados para o preparo de ração (FAO, 1990). Nos processos de comercialização e industrialização do pescado, 20 milhões de toneladas são descartadas como partes não aproveitáveis (Rebeca, 1991). Esse descarte poderia estar sendo utilizado para alimentação animal.

O objetivo desse trabalho foi avaliar o ganho de peso, incremento no comprimento focinho-cloaca (CFC), taxa de crescimento e de ganho de peso em filhotes de jacaré-de-papo-amarelo durante o primeiro ano de vida, alimentados com quatro diferentes dietas: peixe, suíno, frango e mistura dessas três fontes protéicas, oriundas de descarte de produção animal.

\section{MATERIAL E MÉTODOS}

O estudo foi conduzido no Setor de Animais Silvestres do Departamento de Produção Animal da Escola Superior de Agricultura "Luiz de Queiroz" (ESALQ), Universidade de São Paulo, durante o período de maio de 1996 a maio de 1997.

Foram utilizados animais pertencentes à colônia de jacarés-de-papo-amarelo do Setor de Animais Silvestres do Departamento de Produção Animal da ESALQ/USP. O manejo reprodutivo adotado no Setor consiste no monitoramento das posturas, imediata coleta dos ovos e incubação artificial. A incubação é feita em caixas de isopor com temperatura controlada através de um termostato. Os ovos são acondicionados no substrato vermiculita, dentro de bandejas plásticas. A umidade é mantida em torno do ponto de saturação, através da manutenção da água no fundo da caixa a uma profundidade de $5 \mathrm{~cm}$, conforme descrito por Verdade et al. (1992a).

Os filhotes que participaram do experimento foram fêmeas, totalizando 120 animais, oriundos de seis diferentes ninhadas. O ninho de origem é uma importante fonte de variação (Hutton, 1987; Larriera \& Del Barco, 1990, Gregory \& Prelypchan, 1994) e deve ser considerado em experimentos, distribuindo-se os animais das diferentes ninhadas em todos os tratamentos (Staton et al., 1990b).

Para avaliação do crescimento e ganho de peso de jacaré-de-papo-amarelo foram testadas quatro dietas: peixe, suíno, frango, peixe + suíno + frango.

Esses alimentos foram escolhidos devido ao grande volume e constância de descarte que ocorre nessas produções animais (Verdade et al., 1990; Walker et al.,1993; Oetterer, 1993/94). Os alimentos (Tabela 1) foram obtidos na própria USP/ESALQ, através da pesca e descartes dos Setores de Suinocultura, Avicultura e Piscicultura. O processamento adotado foi a moagem do peixe e leitão inteiros, incluindo as vísceras. O frango passou previamente pela retirada das penas e posterior moagem. Toda a moagem foi feita com discos de saída de $1,2 \mathrm{~cm}$ de diâmetro.

Os animais receberam alimentação cinco vezes por semana, considerada uma frequência adequada para um bom desenvolvimento dos filhotes (Joanen \& McNease, 1981,1987; McNease \& Joanen, 1981; Staton et al., 1990a). A quantidade de alimento fornecido foi de $3 \%$ do peso vivo por dia, descrito por Joanen \& McNease (1987) e Staton et al. (1989) como quantidade de alimento suficiente para proporcionar boas taxas de crescimento sem deixar sobras em excesso. Essas quantias foram estabelecidas mensalmente após as biometrias. $O$ estabelecimento de um limite de consumo foi feito a fim de evitar preferência dos animais pelo alimento mais palatável, aumentando assim o seu consumo. Segundo Pinheiro (1996) quando o alimento é fornecido ad libitum a influência dos componentes das dietas pode ser confundida com a diferença do consumo entre elas. Desta forma pode-se avaliar o tratamento que propiciou os melhores resultados com maiores incrementos no peso e comprimento dos filhotes, partindo da mesma quantidade (proporcional) de alimento fornecido.

$\mathrm{O}$ alimento foi fornecido na forma de pequenos aglomerados, compatíveis com o tamanho da boca dos animais, colocados na interface "água - piso seco", conforme proposto por Verdade et al. (1992b). Isto ocorreu no período mais quente do dia, ao redor do meiodia. O recolhimento das sobras foi feita uma hora após o fornecimento do alimento.

A área experimental foi uma composta por cinco módulos, dos quais foram utilizados apenas quatro. Cada módulo possui uma área seca e um tanque, condição que permite ao animal procurar o sol ou a água no decorrer do dia. A área de cada módulo é de $10 \mathrm{~m}^{2}$, com cerca de $70 \%$ de área seca. Os tanques medem $0,56 \mathrm{~m}$ de largura $\times 3,91 \mathrm{~m}$ de comprimento $\times 0,46 \mathrm{~m}$ de profundidade. A temperatura média mensal do ar durante o período experimental pode ser vista na Tabela 2.

Os animais passaram por medições de comprimento do focinho à cloaca, largura da pele ventral em sua porção mediana (largura comercial) e pesagens mensais. Os filhotes foram capturados com puçá ou manualmente após o esgotamento total do tanque. Devido ao pequeno porte, não foi preciso imobilizar a boca dos animais para a realização da biometria.

$O$ delineamento experimental foi em blocos completos casualizados. Foram testados quatro tratamentos em seis blocos, representados pelas diferentes ninhadas. Cada tratamente foi aplicado a 30 animais. Cada animal representava uma unidade experimental, isolando dessa forma, os tratamentos e as ninhadas como fonte de variação.

Os resultados foram avaliados através da análise de variância (ANOVA) pelo programa Minitab (1996). 
Tabela 1 - Composição bromatológica das dietas experimentais, expressa em matéria seca.

\begin{tabular}{|c|c|c|c|c|c|c|c|c|c|c|}
\hline Amostra & MS & MM & EE & FB & PB & $\mathrm{Ca}$ & $P$ & Ca:P & EB & EB:PB \\
\hline & -----. & -----. & - & 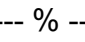 & --- & - - - & -------_- & & $\mathrm{cal} \mathrm{g}^{-1}$ & \\
\hline Peixe & 30,7 & 18,8 & 23,7 & 1,24 & 53,7 & 5,17 & 2,98 & 1,73 & 4945,05 & 9,21 \\
\hline Suíno & 28,9 & 14,6 & 18,6 & 0,71 & 56,8 & 4,4 & 2,45 & 1,8 & 4889 & 8,61 \\
\hline Frango & 37,3 & 7,8 & 33,3 & 1,12 & 48,9 & 1,18 & 1,35 & 0,87 & 5580,25 & 11,42 \\
\hline Mistura & 31,8 & 17,1 & 23,6 & 0,56 & 48,9 & 4,46 & 2,83 & 1,58 & 5249,05 & 10,74 \\
\hline
\end{tabular}

$\mathrm{MS}=$ matéria seca, expressa a $60^{\circ} \mathrm{C} . \mathrm{MM}=$ matéria mineral; $\mathrm{EE}=$ extrato etéreo; $\mathrm{FB}=$ fibra bruta; $\mathrm{PB}=$ proteína bruta; $\mathrm{Ca}=\mathrm{cál}(\mathrm{cio} ; \mathrm{P}=$ fósforo; $\mathrm{EB}=$ energia bruta

Tabela 2 - Temperatura do interior da estufa plástica durante o período experimental.

\begin{tabular}{|c|c|c|c|}
\hline & T máx. & T mín. & $\mathrm{T}^{\circ} \mathrm{C}$ média \\
\hline & ---------- & $-{ }^{\circ} \mathrm{C}-$ & - \\
\hline Mai/96 & 32,4 & 17,5 & 24,9 \\
\hline Jun/96 & 29,9 & 14,8 & 22,3 \\
\hline Jul/96 & 30,9 & 13,4 & 22,1 \\
\hline Ago/96 & 32,9 & 16,1 & 24,5 \\
\hline Set/96 & 33,3 & 20 & 26,6 \\
\hline Out/96 & 33,7 & 22 & 27,8 \\
\hline Nov/96 & 41,8 & 19 & 30,4 \\
\hline Dez/96 & 44,5 & 21,9 & 33,2 \\
\hline Jan/97 & 41,4 & 22,4 & 31,9 \\
\hline Fev/97 & 41,6 & 21,8 & 31,7 \\
\hline Mar/97 & 38,9 & 18,7 & 28,8 \\
\hline Abr/97 & 33 & 20,6 & 26,8 \\
\hline Mai/97 & 31,9 & 17,8 & 24,8 \\
\hline
\end{tabular}

Todos os dados do comprimento apresentaram distribuição normal. Foi feita transformação logarítmica dos dados de massa corpórea, com a finalidade de normalizar sua distribuição.

\section{RESULTADOS E DISCUSSÃO}

Não houve diferença entre os tratamentos com relação aos valores iniciais das variáveis massa corpórea $(P=0,822)$, comprimento focinho- cloaca $(P=0,621)$ e largura ventral comercial $(P=0,736)$, evidenciando homogeneidade das parcelas que compunham cada tratamento. Houve efeito de tratamento em março/97 ( $P=$ $0,004)$ e através do teste de Tukey de comparação de médias a $5 \%$ constatou-se que os animais que consumiram a dieta composta por mistura foram mais pesados que aqueles que se alimentaram da dieta composta por peixe. Nos meses abril $(P<0,001)$ e maio/ $97(P=0,001)$, a dieta composta por peixe apresentou resultados inferiores, diferindo estatisticamente das dietas compostas por suíno e mistura. Os demais tratamentos não apresentaram diferenças significativas entre si em todo o período experimental. O peso médio dos diferentes tratamentos durante o período experimental é apresentado na Tabela 3.

A massa corpórea final dos animais variou de 605,2 a $1084,9 \mathrm{~g}$ e foi inferior aos resultados encontrados por Pinheiro (1996), que obteve filhotes de jacaré-depapo-amarelo aos 13 meses de idade com peso médio entre 1683 a 2431 g. O autor trabalhou com apenas 16 animais, sendo grande parte deles machos, alimentados com diferentes dietas (frango, suíno, peixe e mistura dessas fontes protéicas), oriundas de descarte de produção animal. Marques \& Monteiro (1995) trabalhando com jacaré-do-pantanal tiveram animais com um ano com peso médio de $1195,7 \mathrm{~g}$.

Os resultados do presente estudo foram, no entanto, superiores a outros trabalhos encontrados na literatura. Larriera (1990) relatou peso médio de $244 \mathrm{~g}$ para animais com 13 meses. Esse resultado pode ter sido influenciado pelas baixas temperaturas (não especificadas pelo autor) do inverno na região. Vianna (2000), também trabalhando com jacarés-de-papoamarelo, encontrou peso médio aos 11 meses variando de 582,8 a $663,2 \mathrm{~g}$ de acordo com a percentagem de farelo de soja incluído na dieta. Piña et al. (1996) obtiveram filhotes de jacaré-de-papo-amarelo aos 6 meses pesando $143,9 \mathrm{~g}$, quando alimentados com peixe; e 159,5 g quando receberam dieta à base de frango.

As curvas de crescimento são representadas na Figura 1 para os tratamentos Peixe $\left(R^{2}=0,8433\right)$, Suíno $\left(R^{2}=0,8697\right)$, Frango $\left(R^{2}=0,8285\right)$ e Mistura $\left(R^{2}=\right.$ 0,8477), respectivamente (SAS, 1993; Minitab, 1996). A aplicação do teste $t$ entre os coeficientes angulares, mostrou que as curvas dos quatro tratamentos não diferiram. Todas elas foram mais bem expressas em termos de seu coeficiente de determinação, pelo modelo exponencial. Este padrão pode ser interpretado pela fase da vida do jacaré em que o presente estudo foi conduzido: durante seu primeiro ano de vida. Ainda que o crescimento dos crocodilianos não se encaixe perfeitamente em nenhum modelo matemático (Abercrombie, 1992, 1996), podemos assumir sem receio que ele não permaneça exponencial durante toda a vida dos animais, mas restrinja-se à sua fase inicial (Brisbin, 1990). Do ponto de vista de sua produção comercial, esta é a fase mais importante.

Através do teste $t$ (de student) de comparação de médias 2 a 2 , verificou-se que as taxas de ganho de peso não apresentaram diferença estatística $(P>0,05)$ entre os tratamentos (Tabela 4).

Para transformação dos dados utilizou-se a Taxa de Crescimento Específica (TCE): TCE $=100 \times[(\log$ peso final $-\log$ peso inicial)/N], sendo $\mathrm{N}=$ número de animais em cada tratamento. A Taxa de Crescimento Específica 
foi dividida em quatro períodos: TCE ${ }_{1-13}$ : período experimental total; TCE ${ }_{1-5}$ : maio a agosto; TCE ${ }_{5-9}$ : setembro a dezembro; $\operatorname{TCE}_{9-13}^{13}$ : janeiro a maio.

Os ganhos de peso de cada período podem ser observados na Tabela 5 . Houve efeito de tratamento $(P<0,01)$ no período experimental todo. Os animais que consumiram dieta composta por peixe tiveram o menor ganho de peso, diferindo das dietas compostas por suíno e mistura $(P<0,05)$. Os animais alimentados com dieta composta por frango apresentaram um menor ganho de peso quando comparados àqueles que consumiram dieta composta por mistura $(P<0,05)$. Os demais tratamentos não apresentaram diferença entre si $(P>0,05)$.

No período de maio a agosto novamente houve diferença entre os tratamentos $(P=0,002)$. A dieta composta por peixe apresentou ganho de peso inferior, diferindo $(P<0,05)$ das dietas compostas por suíno e mistura. Os demais tratamentos tiveram o mesmo comportamento com relação ao ganho de peso. Finalmente, de janeiro a maio $(P<0,00)$ a dieta composta por mistura foi diferente estatisticamente das dietas compostas por peixe e frango, apresentando um maior ganho de peso. O ganho de peso variou entre os diferentes períodos do ano. Os maiores ganhos de peso ocorreram no período final do experimento, quando se obteve um ganho de 2,3 a $5 \mathrm{~g} \mathrm{dia}^{-1}$ (Tabela 5). Nesse período do ano a temperatura dentro da estufa estava alta, principalmente nos meses janeiro $\left(31,9^{\circ} \mathrm{C}\right)$ e fevereiro $\left(31,7^{\circ} \mathrm{C}\right)$, diminuindo gradativamente até maio (Tabela 2). Os animais podem ter alcançado os maiores ganhos de peso devido ao fato de acumularem calor durante esse período.

Pinheiro (1996) obteve ganhos de peso de 244,2 g a $371,1 \mathrm{~g} \mathrm{mês}^{-1}\left(8,14\right.$ a $\left.12,37 \mathrm{~g} \mathrm{dia}^{-1}\right)$, variando conforme o descarte utilizado, dos meses de novembro a maio. Staton et al. (1990a) trabalhando com filhotes de aligátores de aproximadamente $850 \mathrm{~g}$, verificaram ganhos de peso entre 196 e $696 \mathrm{~g} \mathrm{mês}^{-1}$. O alimento fornecido era ração formulada para aligátores, variando a frequência de alimentação.
Com relação à variável comprimento focinhocloaca, a dieta composta por mistura foi a melhor diferindo da dieta composta por peixe nos meses março $(P=0,012)$, abril $(P=0,023)$ e maio $(P=0,012)$ de 1997. Os demais tratamentos não diferiram. O comprimento focinho-cloaca (Tabela 6) variou de 27,6 a $32,7 \mathrm{~cm}$. Essa medida corresponde a aproximadamente metade do comprimento total (Verdade, 2000). Não foi utilizado o comprimento total porque é muito comum filhotes perderem a ponta da cauda em brigas, fato que poderia influenciar o resultado final.

Os resultados foram inferiores aos resultados de Pinheiro (1996), que obteve aos 13 meses de idade filhotes de jacaré-de-papo-amarelo medindo entre 36,5 e 39,6 cm de comprimento focinho-cloaca. Vianna et al. (1995) relatam que filhotes de jacaré-de-papo-amarelo de 120 dias mediram de 32,8 a $42,3 \mathrm{~cm}$ de comprimento total, e que essa variação foi causada pelas diferentes temperaturas ambientes a que os animais foram submetidos. Vianna (2000) verificou que o comprimento focinho-cloaca de animais alimentados com dietas contendo farelo de soja variou de 23,6 a $25,7 \mathrm{~cm}$, conforme a percentagem de farelo de soja incluída na dieta. Piña et al. (1996) obtiveram jacarés-de-papoamarelo de 6 meses de idade medindo de $37,6 \mathrm{~cm}$ a

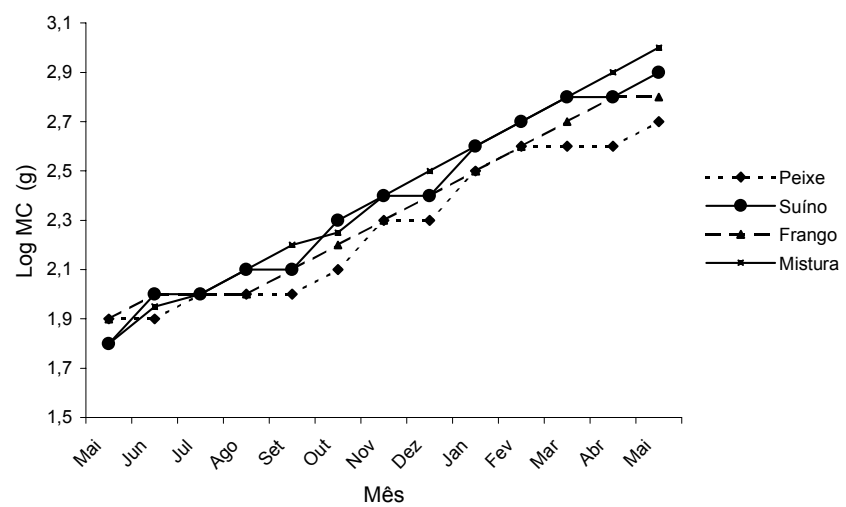

Figura 1 - Curva de crescimento para Log massa corpórea (MC) de jacarés-de-papo-amarelo alimentados com dieta composta por Peixe, Suíno, Frango e Mistura.

Tabela 3 - Peso médio de jacarés-de-papo-amarelo alimentados com quatro dietas durante o primeiro ano de vida.

\begin{tabular}{|c|c|c|c|c|c|}
\hline Mês & Peixe & Suíno & Frango & Mistura & C.V. \\
\hline & & & & - & 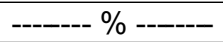 \\
\hline Mai/96 & $75,50 \mathrm{a}$ & $72,60 \mathrm{a}$ & $74,07 \mathrm{a}$ & $70,97 a$ & 6,27 \\
\hline Jun/96 & 91,07 a & 94,26 a & $101,63 a$ & $93,27 \mathrm{a}$ & 6,91 \\
\hline Jul/96 & $106,50 \mathrm{a}$ & 114,30 a & $122,33 a$ & $121,73 \mathrm{a}$ & 8,08 \\
\hline Ago/96 & $113,10 a$ & $127,10 \mathrm{a}$ & $122,76 a$ & $126,63 \mathrm{a}$ & 7,90 \\
\hline Set/96 & $128,50 a$ & $149,50 a$ & $135,48 a$ & $148,26 a$ & 8,71 \\
\hline Out/96 & $148,87 \mathrm{a}$ & 192,83 a & $168,35 a$ & $182,17 \mathrm{a}$ & 8,92 \\
\hline Nov/96 & $212,20 a$ & $269,37 a$ & $239,97 a$ & $273,03 a$ & 8,42 \\
\hline Dez/96 & 242,86 a & 286,03 a & $287,69 a$ & $319,80 a$ & 8,43 \\
\hline Jan/97 & $324,30 a$ & $411,13 a$ & $425,62 a$ & $461,41 \mathrm{a}$ & 8,71 \\
\hline Fev/97 & $416,10 \mathrm{a}$ & 525,27 a & $559,89 a$ & $596,24 \mathrm{a}$ & 9,46 \\
\hline Mar/97 & $467,03 a$ & $631,10 a$ & $689,03 a$ & $785,25 b$ & 8,76 \\
\hline Abr/97 & $514,00 a$ & $769,80 \mathrm{~b}$ & $819,76 a b$ & $970,61 \mathrm{~b}$ & 8,79 \\
\hline Mai/97 & $605,17 \mathrm{a}$ & $848,00 \mathrm{~b}$ & $848,90 \mathrm{ab}$ & $1084,89 \mathrm{~b}$ & 8,67 \\
\hline
\end{tabular}

Médias seguidas de mesma letra não diferem estatisticamente pelo teste Tukey a $5 \%, C . V$. = Coeficiente de variação. 
$36,2 \mathrm{~cm}$ de comprimento total para alimentados com frango e peixe, respectivamente. Trabalhando com filhotes de jacaré-do-pantanal alimentados com carne e vísceras bovinas, Marques \& Monteiro (1995) encontraram filhotes de 12 meses de idade com comprimento total médio de $64 \mathrm{~cm}$. Santos et al. (1993) relatam que o comprimento focinho-cloaca de filhotes de jacaré-do-pantanal aos 88 dias variou de 13,3 a 16,2 $\mathrm{cm}$. Essa variação ocorreu devido às diferentes dietas utilizadas: peixe, crustáceos, moluscos e insetos aquáticos.

As curvas de crescimento são representadas na Figura 2 para os tratamentos Peixe $\left(R^{2}=0,9642\right)$, Suíno $\left(R^{2}=0,9805\right)$, Frango $\left(R^{2}=0,9614\right)$ e Mistura $\left(R^{2}=\right.$ 0,9707), respectivamente (Minitab, 1996; SAS, 1993). O teste $t$ entre os coeficientes angulares constatou-se que as curvas dos quatro tratamentos não diferiram entre si. Todas elas foram melhor expressas, em termos de

Tabela 4 - Log taxa de ganho de peso de jacarés-de-papoamarelo alimentados com quatro dietas durante o primeiro ano de vida.

\begin{tabular}{|c|c|c|}
\hline Dieta & Log taxa de ganho de peso & C.V. \\
\hline & ----- g mês ${ }^{-1}$----- & ----- \% ----- \\
\hline Peixe & 0,86 a & 5,55 \\
\hline Suíno & $1,01 \mathrm{a}$ & 5,66 \\
\hline Frango & $1,01 \mathrm{a}$ & 6,65 \\
\hline Mistura & 1,11 a & 6,71 \\
\hline
\end{tabular}

Médias seguidas de mesma letra não diferem pelo teste $t$ a $5 \%$. C.V.= coeficiente de variação coeficiente de determinação, pelo modelo linear. Esse padrão ocorre porque os dados do presente estudo correspondem ao primeiro ano de vida dos jacarés. Esse modelo matemático, do tipo linear, restringe-se à fase inicial de crescimento dos crocodilianos.

\section{Taxa de crescimento}

Através do teste $t$ de comparação de médias 2 a 2, verificou-se que houve diferença entre as taxas de crescimento dos tratamentos (Tabela 7). A dieta composta pela mistura das três fontes protéicas apresentou a maior $(P<0,05)$ taxa de crescimento. As dietas compostas por suíno e frango não diferiram $(P>0,05)$, mas foram superiores $(P<0,05)$ aos animais alimentados com dieta composta por peixe.

Para essa variável houve efeito de tratamento $(P=0,002)$ no período experimental como um todo. A dieta composta por peixe apresentou um menor incremento $(P<0,05)$ no comprimento, do que as dietas compostas por suíno e mistura. Também houve efeito de tratamento nos períodos de maio a agosto $(P=0,05)$ e de janeiro a maio/97 $(P=0,005)$, onde a dieta composta por peixe apresentou um incremento no comprimento menor $(\mathrm{P}<0,05)$ que a dieta composta por mistura. No período de setembro a dezembro não houve efeito de tratamento $(P=0,081)$.

As taxas de incremento no comprimento focinhocloaca de cada período são apresentadas na Tabela 8. As taxas de crescimento foram maiores $(1,7$ a $2,3 \mathrm{~cm}$

Tabela 5 - Ganho de peso médio de jacarés-de-papo-amarelo alimentados com quatro dietas durante o primeiro ano de vida.

\begin{tabular}{|c|c|c|c|c|c|}
\hline Período & Peixe & Suíno & Frango & Mistura & C.V. \\
\hline & & & & & ------ \% ------- \\
\hline Mai-Mai & $532,67 a$ & 775,72 bc & $774,72 a b$ & $1013,42 \mathrm{c}$ & 23,30 \\
\hline Mai-Ago & $53,00 \mathrm{a}$ & $76,60 \mathrm{~b}$ & $61,30 a b$ & $82,28 \mathrm{~b}$ & 55,14 \\
\hline Set-Dez & $198,80 a$ & 261,97 a & $290,14 a$ & $320,89 a$ & 33,59 \\
\hline Jan-Mai & $280,87 \mathrm{a}$ & $436,87 \mathrm{ab}$ & $423,28 \mathrm{a}$ & $610,25 \mathrm{~b}$ & 27,23 \\
\hline
\end{tabular}

Médias seguidas de mesma letra não diferem pelo teste t a 5\%. C.V.= coeficiente de variação.

Tabela 6 - Comprimento médio do focinho-cloaca de jacarés-de-papo-amarelo alimentados com quatro dietas durante o primeiro ano de vida.

\begin{tabular}{|c|c|c|c|c|c|}
\hline Data & Peixe + dpm & Suíno + dpm & Frango + dpm & Mistura + dpm & C.V. \\
\hline & & - & & -- & ---- \% ----- \\
\hline Mai/96 & $14,07 a+0,22$ & $14,52 a+0,19$ & $14,56 a+0,21$ & $14,32 a+0,23$ & 12,05 \\
\hline Jun/96 & $15,40 a+0,29$ & $15,23 a+0,24$ & $15,57 a+0,28$ & $15,20 a+0,28$ & 13,56 \\
\hline $\mathrm{Jul} / 96$ & $16,08 a+0,37$ & $16,21 a+0,28$ & $16,40 a+0,35$ & $16,38 a+0,33$ & 15,37 \\
\hline Ago/96 & $16,13 a+0,27$ & $16,69 a+0,33$ & $16,61 a+0,38$ & $16,61 a+0,34$ & 16,30 \\
\hline Set/96 & $16,71 a+0,44$ & $17,44 a+0,34$ & $17,01 a+0,45$ & $17,30 a+0,36$ & 17,41 \\
\hline Out/96 & $18,12 a+0,53$ & $19,58 a+0,44$ & $18,25 a+0,58$ & $19,28 a+0,43$ & 19,82 \\
\hline Nov/96 & $20,29 a+0,57$ & $21,32 a+0,49$ & $20,54 a+0,68$ & $21,64 a+0,51$ & 20,59 \\
\hline Dez/96 & $22,56 a+1,03$ & $23,06 a+0,50$ & $22,52 a+0,77$ & $23,53 a+0,61$ & 21,84 \\
\hline Jan/97 & $23,64 a+0,67$ & $25,30 a+0,60$ & $25,27 a+0,89$ & $26,21 a+0,71$ & 22,75 \\
\hline Fev/97 & $25,40 a+0,69$ & $26,82 a+0,65$ & $26,42 a+1,02$ & $27,83 a+0,72$ & 23,63 \\
\hline Mar/97 & $26,18 a+0,76$ & $28,53 a b+0,68$ & $28,48 a b+1,05$ & $30,69 b+0,81$ & 23,60 \\
\hline Abr/97 & $26,76 a+0,79$ & $29,55 a b+0,69$ & $28,91 a b+1,12$ & $31,19 b+0,83$ & 24,11 \\
\hline Mai/97 & $27,61 a+0,87$ & $30,65 a b+0,76$ & $30,12 a b+1,18$ & $32,68 b+0,89$ & 24,85 \\
\hline
\end{tabular}

Médias seguidas de mesma letra não diferem estatisticamente pelo teste Tukey a $5 \%$, dpm = Desvio padrão da média, $C . V .=$ Coeficiente de variação. 
mês $^{-1}$ ) no período de setembro a dezembro, período em que a temperatura aumentou gradativamente e chegou a atingir a máxima de $44,5^{\circ} \mathrm{C}$ em dezembro (Tabela 2), diferindo do ganho de peso, que foi maior na fase final do experimento. Isso mostra que possivelmente os animais sofram um processo de alongamento anterior ao ganho de peso no processo de crescimento e desenvolvimento (Verdade, 1997b).

Neste experimento, a taxa de crescimento média durante todo o período experimental variou de 1,1 a $1,5 \mathrm{~cm} \mathrm{mês}^{-1}\left(0,3\right.$ a $\left.0,5 \mathrm{~mm} \mathrm{dia}^{-1}\right)$ e foram inferiores às encontradas por Gorzula \& Seijas (1989), que verificaram uma taxa de crescimento de 2,0 a $2,6 \mathrm{~cm}$ mês ${ }^{-1}$ durante o primeiro ano de vida de Caiman crocodilus crocodilus oriundos de populações selvagens. Marques \& Monteiro (1995) relatam que, ao final de um ano, filhotes de jacaré-do-pantanal mantidos sob temperaturas superiores a $28^{\circ} \mathrm{C}$ apresentaram crescimento de 2,4 cm mês ${ }^{-1}$. Pinheiro (1996) obteve valores de 5,7 a $6,8 \mathrm{~cm}^{\text {mês }}{ }^{-1}$ de crescimento, que é

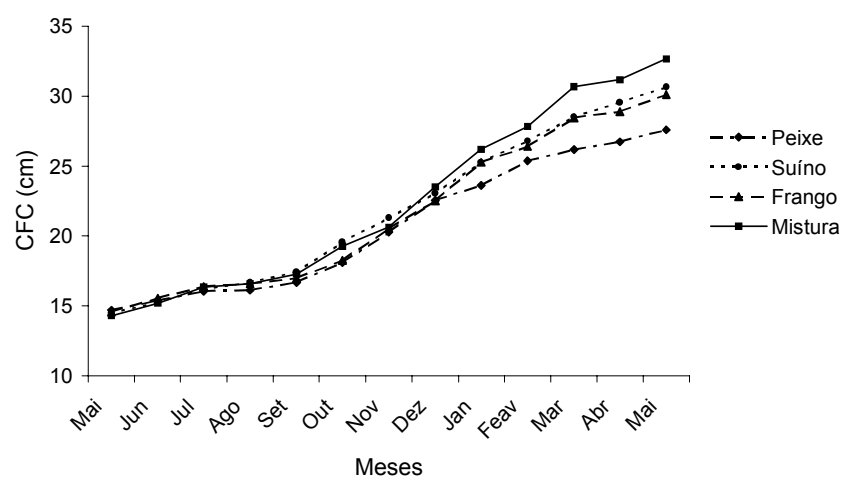

Figura 2 - Curva de crescimento para comprimento focinho-cloaca (CFC) de jacarés-de-papo-amarelo alimentados com dieta composta por Peixe, Suíno, Frango e Mistura

Tabela 7 - Taxa de crescimento de jacarés-de-papo-amarelo alimentados com quatro dietas durante o primeiro ano de vida.

\begin{tabular}{lcc}
\hline Dieta & Taxa de cre scimento & C.V. \\
\hline & ------ ${\text { cm } \text { mês }^{-1}-----}^{------}$ \\
Peixe & $1,21 \mathrm{a}$ & 4,58 \\
Suíno & $1,47 \mathrm{~b}$ & 3,84 \\
Frango & $1,42 \mathrm{~b}$ & 5,36 \\
Mistura & $1,66 \mathrm{c}$ & 5,22 \\
\hline
\end{tabular}

Médias seguidas de mesma letra não diferem pelo teste $t$ a $5 \%$. C.V.= coeficiente de variação equivalente a 0,19 a $0,22 \mathrm{~cm} \mathrm{dia}^{-1}$. O experimento foi conduzido em estufa plástica de novembro a maio e foram utilizados 16 jacarés, sendo a grande maioria machos.

O efeito de ninhada foi significativo ao logo do período experimental para todas as variáveis testadas, como massa corpórea $(P<0,007)$, comprimento focinhocloaca $(P<0,003)$ e largura comercial $(P<0,02)$.

Os resultados encontrados por Pinheiro (1996) foram diferentes dos encontrados neste experimento. $O$ referido autor trabalhando com os mesmos descartes utilizados no presente estudo encontrou maiores ganhos de peso ( $29 \%$ mais pesados) e maiores incrementos em comprimento ( $5 \%$ mais longos) para animais alimentados com tilápia, seguidos da dieta frango, suíno e por último a mistura. No presente estudo, os animais que apresentaram os melhores resultados em crescimento e ganho de peso foram aqueles alimentados com dieta composta por mistura, seguido de suíno, frango e por último o peixe (tilápia). Talvez essa diferença possa ser explicada pelo manejo adotado por Pinheiro (1996), que retirou as vísceras do frango e suíno e moeu o peixe de forma integral. Dessa forma, os tratamentos não foram homogêneos. O autor ainda menciona que as altas taxas de crescimento e ganho de peso ocorreram devido a um provável crescimento compensatório durante o período experimental.

Joanen \& McNease (1987) mencionam a superioridade das carnes vermelhas em relação às brancas, proporcionando maiores taxas de crescimento por serem mais adequadas nutricionalmente. Pinheiro (1996) encontrou uma tendência de maior percentagem de aminoácidos essenciais na matéria seca nas dietas frango, suíno e mistura. As menores porcentagens de aminoácidos essenciais na matéria seca foram encontrados na tilápia.

Larriera \& Aguinaga (1990) também relatam o crescimento superior de Caiman latirostris alimentados com carne vermelha em relação à dieta contendo $70 \%$ de peixe marinho. Comparando dieta à base de frango e dieta composta por curimbatá (Prochilodus lineatus), Piña et al. (1996) encontraram melhores resultados em filhotes de jacaré-de-papo-amarelo alimentados com frango, que foram $11 \%$ mais pesados e $2,3 \%$ mais compridos. Os autores ainda mencionam maior palatabilidade do frango em relação ao peixe. Pooley

Tabela 8 - Incremento médio no comprimento focinho-cloaca de jacarés-de-papo-amarelo alimentados com quatro dietas durante o primeiro ano de vida.

\begin{tabular}{lccccc}
\hline Período & Peixe & Suíno & Frango & Mistura & C.V. \\
\hline Mai-Mai & $-12,91 \mathrm{a}$ & $16,31 \mathrm{~b}$ & $15,56 \mathrm{ab}$ & $18,35 \mathrm{~b}$ & $-\mathbf{- -}$ \\
Mai-Ago & $2,01 \mathrm{a}$ & $2,92 \mathrm{~b}$ & $2,45 \mathrm{ab}$ & $3,16 \mathrm{~b}$ & 61,91 \\
Set-Dez & $6,93 \mathrm{a}$ & $7,86 \mathrm{a}$ & $8,25 \mathrm{a}$ & $9,07 \mathrm{a}$ & 35,49 \\
Jan-Mai & $3,97 \mathrm{a}$ & $5,35 \mathrm{ab}$ & $4,86 \mathrm{ab}$ & $6,12 \mathrm{~b}$ & 42,06 \\
\hline
\end{tabular}

Médias seguidas de mesma letra não diferem pelo teste t a $5 \%$. C.V.= coeficiente de variação 
(1991) sugere a mistura de diferentes fontes protéicas como ideal para um maior desenvolvimento de filhotes de crocodilianos.

As carnes vermelhas proporcionam ainda uma melhor conversão alimentar (Piña et al., 1996). O alimento consumido neste experimento não pode ser quantificado, devido à inviabilidade dessa atividade dentro dos recintos utilizados. A conversão alimentar dos diferentes tratamentos foi estimada a partir da quantidade de alimento fornecido e do ganho de peso total dos animais ao longo do período experimental e variaram de 1,2 a 1,6 $\mathrm{g}$ de matéria seca $\mathrm{g}^{-1}$ de ganho de peso.

Os valores encontrados foram melhores que aqueles encontrados por Pinheiro (1996) que obteve valores entre 2,2 para mistura e 3,6:1 para a dieta composta por peixe. Vianna et al. (1995) relatam valores de conversão alimentar entre 0,8 e 3,2:1. Essa variação se deve às diferentes temperaturas a que os animais foram submetidos. Animais mais velhos apresentam uma pior conversão alimentar (Joanen \& McNease, 1987). Os autores encontraram valores de 1,4:1 para animais de 3 meses de idade e 2:1 para animais com 1 ano.

Com relação aos componentes das dietas, Staton et al. (1990a) encontraram melhores resultados em crescimento de aligátores quando utilizaram dieta contendo Energia Bruta (EB) na faixa de 5.180 a 5.244 $\mathrm{kcal} \mathrm{kg}^{-1} \mathrm{MS}$ e Proteína Bruta (PB) na faixa de 49 a $56 \%$. $A$ relação EB:PB adequada para um bom desenvolvimento dos animais vai de 9,7 a $12,9 \mathrm{~L}$ kcal $\mathrm{g}^{-1}$. Os autores ainda recomendam o uso de 15,8 a $27,4 \%$ de gordura na dieta. Staton et al. (1989) encontraram maiores consumos e ganhos de peso e menor taxa de mortalidade naqueles animais que receberam dieta com $1 \%$ de cálcio e $0,5 \%$ de fósforo (proporção 2:1). A dieta mais adequada para atender às exigências nutricionais mencionadas foi a composta por mistura, e concordando com Pooley (1991) foi a dieta que apresentou as maiores taxas de crescimento e ganho de peso durante todo o período experimental (Tabela 1).

\section{REFERÊNCIAS BIBLIOGRÁFICAS}

ABERCROMBIE, C.L. Fitting curves to crocodilian age-size data: some hesitant recommendations. In: WORKING MEETING OF CROCODILE SPECIALIST GROUP, 11., Gland, Switzerland, 1992. Proceedings. Gland, Switzerland: IUCN - The World Conservation Union, 1992. p.3-4.

ABERCROMBIE, C.L. Summarizing croc growth using the Von Bertalanffy curve. In: WORKING MEETING OF CROCODILE SPECIALIST GROUP, 13., Santa Fé, 1996. Proceedings. Gland: IUCN - The World Conservation Union, 1996. p.237-248

BRISBIN Jr. I.L. Growth curve analysis and their application to the conservation and captive management of crocodilians. In: WORKING MEETING OF CROCODILE SPECIALIST GROUP, 9., Lae, 1990. Proceedings. Gland: IUCN - The World Conservation Union, 1990. p.116145.

DIEFENBACH, C.O. da C. Thermal and feeding relations of Caiman latirostris (CROCODYLIA: REPTILIA). Comparative Biochemistry and Physiology, v.89A, p.149-155, 1988.

Scientia Agricola, v.59, n.2, p.243-250, abr/jun. 2002
FIREMAN, F.A.T.; SIEWERDT, F. Efeito do peso ao nascer sobre a mortalidade de leitões do nascimento até 21 dias de idade. Revista Brasileira de Zootecnia, v.26, p.479-484, 1997.

FAO. Anuário Estatístico de la pesca mundial. Roma, 1990. 647p

GORZULA, S.; SEIJAS, A.E. The commum caiman. Crocodiles: their ecology, mangement and conservation. Gland: IUCN - The World Conservation Union, 1989. cap.9, p.44-61.

GREGORY, P.T.; PRELYPCHAN, C.J. Analysis of variance of first-year growth in captive garter snakes (Thamnophis elegans) by family and sex. Journal of Zoology, v.232, p.313- 322, 1994.

HUTTON, J.M. Incubation temperature, sex ratios and sex determination in a population of nile crocodiles (Crocodylus niloticus). Journal of Zoology, v.211, p.143-155, 1987.

JOANEN, T.; McNEASE, L. Propagacion en cautividad de los lagartos en Louisiana. In: INTERNATIONAL CONGRESS OF HERPETOLOGY, Oxford, 1981. Proceedings. Oxford,1981. p.37-46.

JOANEN, T.; McNEASE, L. Alligator farming research in Louisiana, USA. In: WEBB, G.J.W.; MANOLIS, S.C.; WHITEHEAD, P.J. (Ed.) Wildlife mangement: crocodiles and alligators. Chipping Norton: Surrey Beatty, 1987. cap.32, p.329-340.

LARRIERA, A. Observaciones sobre el crecimiento de Caiman latirostris (Daudin, 1802) nacidos en cautiverio II. Peso y longitud a los 30 meses de edad (Crocodylia: Alligatoridae). Amphibia y Reptilia (Conservación), v.1, p.118-119, 1990

LARRIERA, A.; AGUINAGA, M. Crescimento de yacarés, Caiman latirostris (Daudin, 1802), bajo dos diferentes dietas (Crocodylia: Alligatoridae) Amphibia y Reptilia (Conservación), v.1, p.112-114, 1990.

LARRIERA, A.; DEL BARCO, D. Observaciones sobre el crecimiento de Caiman latirostris Daudin, 1802, nascidos en cautiverio. (REPTILIA: ALLIGATORIDAE). Acta Zoology Lilloana, v.41, p.329-339, 1990.

MARQUES, E.J.; MONTEIRO, E.L. Ranching de Caiman crocodilus yacare no Pantanal de Mato Grosso do Sul, Brasil. In: LARRIERA, A.; VERDADE, L.M. (Ed.) La conservación y el manejo de caimanes y cocodrilos de América Latina. Santa Fé: Fundación Banco Bica, 1995. cap.12, p.189-211.

McNEASE, L.; JOANEN, T. Nutricion de los lagartos. In: KING, F.W. (Ed.) Crianza de cocodrilos: informacion de la literatura cientifica. Gland: IUCNThe World Conservacion Union, 1981. p.56-64.

MICUCCI, P.A.; WALLER, T. Los yacares en Argentina: hacia un aprovechamiento sustentable. In: LARRIERA, A.; VERDADE, L.M. (Ed.) La conservación y el manejo de caimanes y cocodrilos de América Latina. Santo Tomé: Fundación Banco Bica, 1995. v.1, cap.6, p.81-112.

MINITAB. Minitab for Windows Release 11. State College: Minitab Inc., 1996.

OETTERER, M. Produção de silagem a partir da biomassa residual do pescado. Alimentos e Nutrição, v.5, p.119-134, 1993/94.

PIÑA, C.; FINCK, C. von; AMAVET, P. Grow rates of Caiman latirostris under two different diets. In: WORKING MEETING OF CROCODILE SPECIALIST GROUP, 13., Santa Fé, 1996. Proceedings. Gland: IUCN - The World Conservation Union, 1996. p.284-289.

PINHEIRO, M.S. Crescimento de filhotes de jacaré-de-papo-amarelo, Caiman latirostris (Daudin, 1802), alimentados com fontes protéicas de origem animal. Piracicaba, 1996. 86p. Dissertação (Mestrado) - Escola Superior de Agricultura "Luiz de Queiroz", Universidade de São Paulo.

POOLEY, A.C. Food and feeding habits. In: ROSS, C.A. (Ed.) Crocodiles and alligators. Silverwater: Golden Press, 1989. p.76-91.

POOLEY, T. Bases para la crianza de cocodrilos en zonas remotas. In: KING F.W. (Ed.) Crianza de cocodrilos: información de la literatura científica. Gland: Grupo de Especialistas en Cocodrilos, IUCN - The World Conservation Union, 1991. p.81-103.

REBECA, B.D.; PEÑA-VERA, M.T.; DÍAZ-CASTANEDA, M. Production of fish hydrolysates with bacterial proteases, yield and nutritional value. Journal of Food Science, v.56, p.309-314, 1991.

RODRIGUEZ-M., M.A.; CLAVIJO-C., L.A.; LÓPEZ-F., O.; GERARDINO, A. de; CEBALLOS-F., C.; ARBOLEDA-C., J.J.; SILVA-M., A.E.; GUERRERO, P.H. Avances en la nutricion de Caiman crocodilus. In: WORKING MEETING OF THE CROCODILE SPECIALIST GROUP, 13., Santa Fé, 1996. Proceedings. Gland: IUCN - The World Conservation Union, 1996. p.347-354.

SANTOS, S.A.; PINHEIRO, M.S.; SILVA, R.A. Efeitos de diferentes dietas naturais no desenvolvimento inicial de Caiman crocodilus yacare (Crocodilia alligatoridae). Revista da Sociedade Brasileira de Zootecnia v.22, p.406-412, 1993

SAS INSTITUTE. SAS user's guide: statistics. Cary: Statistical Analyses System Institute, 1993. v.2.

STATON, M.A.; BRISBIN JR., I.L.; PESTI, G.M. Feed Formulation for alligators: na overview and initial studies. In: WORKING MEETING OF THE CROCODILE SPECIALIST GROUP, 8., Equador, 1986. Proceedings Gland: IUCN - The World Conservation Union, Quito, 1989. p.84-104.

STATON, M.A.; EDWARDS, H.M.; BRISBIN JR., I.L.; JOANEN, T.; McNEASE, $L$. Protein and energy relationships in the diet of American alligator (Alligator mississippiensis). Journal of Nutrition, v.120, p.775-785, 1990a. 
STATON, M.A.; EDWARDS, H.M.; BRISBIN JÚNIOR, I.L.; JOANEN, T.; McNEASE, L. Essential fatty acid nutrition of American alligator (Alligator mississippiensis). Journal of Nutrition, v.120, p.674-685, 1990b.

VERDADE, L.M. Manejo e conservação do jacaré-de-papo-amarelo (Caiman latirostris) no estado de São Paulo, Brasil. In: VALLADARES-PÁDUA, C.B.; BODMER, R.E.; CULLEN Jr., L. (Ed.) Manejo da vida silvestre para a conservação. Brasília: CNPq, 1997a. p.222-232.

VERDADE, L.M. Morphometric analysis of the broad-snouted caiman (caiman latirostris): an assessment of individuals clutch, body size, sex, age and area of origin. Gainesville, 1997b. 171p. Tese (Doutorado) - University of Florida.

VERDADE, L.M. Regression equations between body and head measurements in The broad-snouted caiman (Caiman latirostris). Revista Brasileira de Biologia, v.60, p.469-482, 2000.

VERDADE, L.M.; LAVORENTI, A.; MORAES E SILVA, R.D. Potencial de utilização de carcaças e refugos de granjas avícolas na alimentação do jacaré-de-papo-amarelo (Caiman latirostris) no Estado de São Paulo. In: REUNIÃO ANUAL DA SOCIEDADE BRASILEIRA DE ZOOTECNIA, 27. Campinas, 1990. Anais. Piracicaba: FEALQ, 1990. p.223.

VERDADE, L.M.; MICHELOTTI, F.; RANGEL, M.C.; CULLEN JR., L.; ERNANDES, M.M.; LAVORENTI, A. Manejo dos ovos de jacaré-de-papoamarelo (Caiman latirostris) no CIZBAS/ESALQ/USP. In: WORKSHOP SOBRE CONSERVAÇÃO E MANEJO DO JACARÉ-DE-PAPO-AMARELO (Caiman latirostris), 2., Piracicaba, 1992. Anais. Piracicaba: ESALQ, Depto. de Zootecnia, 1992a. p.92-99.
VERDADE. L.M.; MICHELOTTI, F.; RANGEL, M.C.; CULLEN JR., L.; ERNANDES, M.M.; LAVORENTI, A. Manejo alimentar de filhotes de jacaréde-papo-amarelo (Caiman latirostris, Daudin, 1802) em cativeiro. In: WORKSHOP SOBRE CONSERVAÇÃO E MANEJO DO JACARÉ-DEPAPO-AMARELO (Caiman latirostris), 2., Piracicaba, 1992. Anais. Piracicaba: ESALQ, Depto. de Zootecnia, 1992b. p.77-91.

VIANNA, V.O. Uso de dietas artificiais no desenvolvimento inicial do tracajá (Podocnemis unifilis), tigre d'água (Trachemis dorbignyi), teiú (Tupinambis merianae) e jacaré-de-papo-amarelo (Caiman latirostris) em cativeiro. Jaboticabal, 2000. 166p. Tese (Doutorado) - Faculdade de Ciências Agrárias e Veterinárias, Universidade Estadual Paulista "Júlio de Mesquita Filho".

VIANNA, V.O.; LAVORENTI, A.; SARKIS, F. Efeito da temperatura no desenvolvimento de filhotes de jacaré-de-papo-amarelo, Caiman latirostris (Daudin, 1802) em cativeiro. In: REUNIÃO ANUAL DA SOCIEDADE BRASILEIRA DE ZOOTECNIA, 32., Brasília, 1995. Anais. Brasília: SBZ, 1995. p.391-393.

WALKER, W.R.; LANE, T.J.; JENNINGS, E.W. Alligator production in swine farm lagoons as a means of economical and environmentally safe disposal of dead pigs. In: REUNION REGIONAL DEL GRUPO DE ESPECIALISTAS EN COCODRILOS, 1., Santa Marta, 1991. Memorias. Gland: IUCN The World Conservation Union, 1993. p.247-253.

Recebido em 18.12 .00 